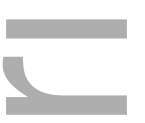

\title{
Colloid fluids in adult anaesthesia and ICU
}

\section{(invited Editorial)}

David A Story; MBBS, MD, BMedSci, FANZCA

Title: Professor and Foundation Chair of Anaesthesia

Affiliation: Anaesthesia, Perioperative and Pain Medicine Unit, The University of Melbourne, Victoria, Australia

Email: dastory@unimelb.edu.au

Colloids are molecules that have limited capacity to move between fluid compartments separated by a semi permeable membrane due to the size of the colloid molecules. Colloid molecules are usually between one nanometre and one micrometre in diameter and behave differently from solutes such as sodium chloride in solution, and particles in a suspension. Because of these properties, colloids are a separate branch of chemistry with practical applications including whipped cream, Styrofoam and intravenous fluids. Theoretically colloids in intravenous fluids would be less likely to cross into the extravascular space therefore maintaining intravascular volume their plasma oncotic effects as well as causing less tissue oedema than crystalloid fluids. There are a number of colloids available for clinical use with different fundamental molecules[1]: albumin, gelatin, dextrans, and starches. In this edition of Paediatric Anaesthesia Witt and colleagues from Germany[2] have examined the effect of large volumes of starch and gelatin colloid fluids on renal function in a piglet model. They found no clinical chemistry or biopsy evidence of acute kidney injury (AKI) in this paediatric animal model. In understanding why Witt and colleagues conducted this study we must look at the colourful recent history of clinical use of colloids in adults.

This is the author manuscript accepted for publication and has undergone full peer review but has not been through the copyediting, typesetting, pagination and proofreading process, which may lead to differences between this version and the Version of Record. Please cite this article as doi: $10.1111 /$ pan. 12853

This article is protected by copyright. All rights reserved 
Fifteen years ago after two conflicting meta-analyses of colloids in adult ICU patients the Australian and New Zealand Intensive Care Society (ANZICS) Clinical Trials Group conducted the what was then largest randomized ICU trial ever undertaken, the SAFE study [3], with $\mathrm{t}$ the hypothesis that $4 \%$ albumin and normal saline are associated with similar 28-day mortality when used for fluid resuscitation in adult ICU patients. In a study of 7,000 patients (43\% surgical) the findings confirmed of the SAFE study hypothesis: relative risk of death $0.99 ; 95 \% \mathrm{Cl}: 0.91$ to 1.09 . There were also some important secondary findings. First, the overall ratio of the volume of albumin to the volume of saline administered during the first four days was approximately 1 to 1.4 ; suggesting that colloids may be far less efficient in maintaining intravascular volume than previously thought. Second, a planned sub-analysis concluded that colloid was associated with increased risk of death for patients with brain injury (RR 1.62; $95 \% \mathrm{Cl}: 1.12$ to 2.34). The SAFE investigators also conducted a post-hoc analysis of the subgroup of patients with sepsis and found albumin was associated with fewer deaths with death OR of 0.71 ( $95 \% \mathrm{Cl}: 0.52$ to 0.97 ). Further, in response to emerging concerns about colloids particularly starches and adverse renal effects the authors also noted that albumin colloid was not associated with increased renal replacement therapy.

Gelatin colloids were introduced as an alternative to human albumin removing the association with blood products and at lower cost in many countries. Starch colloids were introduced as a non-protein (less anaphylaxis), non-blood product (less concern about infectious risk and cultural objections) synthetic colloid alternative. The complexities of the different starch preparations are beyond the remit of this commentary but the starches can be divided into older penta-starches and newer tetrastarches[4]. Over the last five years there has been increasing concern about the starches [5] exacerbated by the rise and fall of Joachim Boldt [6], an anaesthesiologist who has had almost 90 studies retracted for scientific misconduct, many on clinical use of starch colloids. There has been a number of studies associating AKI with starches [4], something Boldt notably failed to detect [6], undermining meta-analyses using his work. A recent meta-analysis of colloids versus crystalloids in critically ill, trauma and surgical patients[4], that excluded Boldt papers, found that that starches and gelatins (the fluids tested by Witt and Colleagues [2]) are not associated with increased mortality (OR $0.99,95 \% \mathrm{Cl}: 0.92$ to 1.06 ), but are associated with greater risk of AKI compared to crystalloids (OR $1.35,1.17$ to 1.57 ) particularly in patients with sepsis. Importantly much of the evidence is limited especially for gelatins.

A confounder is that colloids for clinical use have (approximately isotonic) crystalloid carrier solutions that can have high chloride concentrations [1], notably tetra-starch in saline. One of the many debates in adult fluid practices is the possible association between chloride content of fluids and AKI, particularly between normal (or abnormal) saline and the "balanced" fluids such as Hartmann's (Ringers Lactate) and Plasmalyte. A recent meta-analysis of high-versus low-chloride content fluids in perioperative and critical care fluid resuscitation in 6,200 patients found that high-chloride fluids did not affect mortality (RR $1 \cdot 13,95 \% \mathrm{Cl}: 0.92,1.39$;) but were associated with a significantly higher risk of $\mathrm{AKI}(\mathrm{RR} 1 \cdot 64,1 \cdot 27$ to $2 \cdot 13)[7]$. 
Currently in adult anaesthesia and ICU practice, many would not use colloids in patients with brain injury but may consider non-starch colloids for patients with sepsis. Many hospitals no longer stock starches in line with European and US warnings including an FDA "Black box" warning not to use starches in critically ill adults including those with sepsis[6]. Overall there may be greater use of "balanced crystalloids" and less use of colloids, and high chloride fluids, notably normal saline [5]. The ANZICS Clinical Trials Group will commence an ICU study comparing saline and Plasmalyte in 2016. In summary there is little, if any, evidence of clinical benefit of colloids particularly starches and gelatin, further colloids are more are more expensive than crystalloids so lack of clinical effectiveness will be partnered with increased costs. In contrast to a growing adult literature suggesting renal injury from colloids, Witt and Colleagues [2] have provided evidence for lack of renal harm from starch and gelatin colloids in a paediatric animal model. This is, however, different from evidence of benefit. Given the current situation in adult anaesthesia and ICU, using colloids in children requires careful thought.

Ethics: No research ethics committee approval was required for this article.

Funding: The article was funded by departmental sources

Disclosure: D Story reports no conflict of interest

1. Rochwerg B, Alhazzani W, Sindi A, Heels-Ansdell D, Thabane L, Fox-Robichaud A, Mbuagbaw L, Szczeklik W, Alshamsi F, Altayyar S et al: Fluid resuscitation in sepsis: a systematic review and network meta-analysis. Annals of internal medicine 2014, 161(5):347-355.

2. Witt et al: Impact of high doses of $6 \%$ hydroxyethyl starch $130 / 0.42$ and $4 \%$ gelatin on renal function in a paediatric animal model. Paediatric anaesthesia 2016.

3. Finfer S, Bellomo R, Boyce N, French J, Myburgh J, Norton R, Investigators SS: A comparison of albumin and saline for fluid resuscitation in the intensive care unit. The New England journal of medicine 2004, 350(22):2247-2256.

4. Qureshi SH, Rizvi SI, Patel NN, Murphy GJ: Meta-analysis of colloids versus crystalloids in critically ill, trauma and surgical patients. The British journal of surgery 2015.

5. Hammond NE, Taylor C, Saxena M, Liu B, Finfer S, Glass P, Seppelt I, Willenberg L, Myburgh J: Resuscitation fluid use in Australian and New Zealand Intensive Care Units between 2007 and 2013. Intensive care medicine 2015, 41(9):1611-1619.

6. Wise J: Boldt: the great pretender. BMJ (Clinical research ed) 2013, 346:f1738.

7. Krajewski ML, Raghunathan K, Paluszkiewicz SM, Schermer CR, Shaw AD: Meta-analysis of high-versus low-chloride content in perioperative and critical care fluid resuscitation. The British journal of surgery 2015, 102(1):24-36.

This article is protected by copyright. All rights reserved 


\section{University Library}

\section{- M M N E R VA A gateway to Melbourne's research publications}

Minerva Access is the Institutional Repository of The University of Melbourne

Author/s:

Story, DA

Title:

Colloid fluids in adult anesthesia and ICU

Date:

2016-03-01

Citation:

Story, D. A. (2016). Colloid fluids in adult anesthesia and ICU. PEDIATRIC ANESTHESIA, 26 (3), pp.230-231. https://doi.org/10.1111/pan.12853.

Persistent Link:

http://hdl.handle.net/11343/290867 